\title{
Ocorrência dos indicadores de risco para a deficiência auditiva infantil no decorrer de quatro anos em um programa de triagem auditiva neonatal de um hospital público
}

\section{Occurence of risk indicators for hearing loss over four years in a neonatal hearing screening program of a public hospital}

\author{
Eliara Pinto Vieira ${ }^{1}$, Elisiane Crestani de Miranda ${ }^{2}$, Marisa Frasson de Azevedo ${ }^{3}$, Michele Vargas Garcia ${ }^{4}$
}

\section{RESUMO}

\begin{abstract}
Objetivo: Comparar a ocorrência dos indicadores de risco para a deficiência auditiva infantil ao longo de quatro anos, em um Programa de Triagem Auditiva Neonatal. Métodos: Foram pesquisados os prontuários de 382 recém nascidos prematuros nascidos no Hospital São Paulo, de 2000 a 2004. Resultados: Em 2000, encontramos 5,9\% de casos de antecedentes familiares/ consangüinidade, a qual aumentou de forma estatisticamente significante para 13,6\% em 2003. A ventilação mecânica aumentou de forma estatisticamente significante de 24,6\% casos em 2000, para 40,2\% em 2004. O número de convulsões em RN foi de 4,2\% em 2000 para 9,8\% em 2004, aumento estatisticamente significante. Encontramos 11,0\% de casos de infecção congênita em 2000, o que caiu para 4,3\% em 2003. No ano de 2002, houve apenas um caso de sífilis, sendo que a ocorrência destas doenças diminuiu nos últimos anos. O HPIV foi de 15,3\% no ano 2000 para 5\% em 2003, com redução estatisticamente significante. Os casos de malformação caíram de 3,4\% no ano 2000 para 0,7\% em 2003. Os casos de ototoxicidade diminuíram de forma estatisticamente significante de 43,2\% em 2000 para 30,0\% em 2003. Conclusão: A análise estatística revelou aumento significante da ocorrência dos antecedentes familiares para a deficiência auditiva, do uso de ventilação mecânica e das convulsões neonatais. Os casos de infecção congênita e hemorragia periintraventricular diminuíram estatisticamente do ano 2000 para 2004. Os casos de malformação, baixo peso e ototoxicidade variaram de forma aleatória entre os anos estudados. E alguns indicadores de risco se mantiveram sem alterações estatisticamente significantes.
\end{abstract}

Descritores: Perda auditiva; Recém-nascido; Indicador de risco; Diagnóstico precoce

\section{INTRODUÇÃO}

As perdas auditivas no Brasil têm sido diagnosticadas por volta dos dois a três anos de idade ${ }^{(1)}$. Durante esse tempo, a criança perde informações auditivas importantes, o que in-

(1) Pós-graduanda em Distúrbios da Comunicação Humana pela Universidade Federal de São Paulo - UNIFESP - São Paulo (SP), Brasil.

(2) Mestre, Fonoaudióloga do Núcleo Integrado de Atendimento, Pesquisa e Ensino em Audição da Universidade Federal de São Paulo - UNIFESP - São Paulo (SP), Brasil.

(3) Doutora, Professor Adjunto do Curso de Fonoaudiologia da Universidade Federal de São Paulo - UNIFESP - São Paulo (SP), Brasil.

(4) Pós-graduanda em Distúrbios da Comunicação Humana, Campo Fonoaudiológico, pela Universidade Federal de São Paulo - UNIFESP - São Paulo (SP), Brasil.

Trabalho realizado na Universidade Federal de São Paulo - UNIFESP - São Paulo (SP), Brasil, tendo recebido Prêmio de Menção Honrosa no XXII Encontro Internacional de Audiologia - EIA/Natal - RN, 2007.

Endereço para correspondência: Michele Vargas Garcia. R. Borges Lagoa, 512/92B, Vila Clementino, São Paulo - SP, CEP 04038-000. E-mail: mifono04@yahoo.com.br

Recebido em: 10/5/2007; Aceito em: 30/8/2007 terfere no desenvolvimento da sua comunicação.

A detecção da deficiência auditiva deve ser rigorosamente observada por todos os profissionais da área de saúde e deve ser uma preocupação de Saúde Pública, propiciando melhoria/ manutenção da qualidade de vida de nossa população infantil e na promoção da saúde auditiva ${ }^{(2)}$.

A Triagem Auditiva Neonatal (TAN) representa uma forma de viabilizar o diagnóstico precoce da deficiência auditiva infantil; sendo que um programa de identificação precoce da deficiência auditiva deve contemplar, além dos procedimentos de triagem auditiva, a pesquisa dos indicadores de risco e o acompanhamento de todos os lactentes que apresentam tais indicadores.

Existem intercorrências pré, peri e pós-natais que podem causar deficiência auditiva e estas intercorrências caracterizam os indicadores de risco.

Os indicadores de risco pesquisados no protocolo da Universidade Federal de São Paulo - UNIFESP( ${ }^{(3)}$ são os seguintes: permanência em UTI Neonatal por 48 horas ou mais; antecedente familiar de perda auditiva ou consangüinidade, 
infecções congênitas (rubéola, sífilis, citomegalovírus, herpes, toxoplasmose e AIDS); anomalias craniofaciais, incluindo as de pavilhão auricular e meato acústico externo; peso ao nascimento menor que $1500 \mathrm{gr}$ e/ou PIG (pequeno para a idade gestacional); hiperbilirrubinemia/exosangüineotransfusão; ototóxicos; meningite bacteriana; apgar de 0-4 no primeiro minuto e de 0-6 no quinto minuto; ventilação mecânica prolongada; síndromes; alcoolismo materno e/ou uso de drogas psicotrópicas na gestação; hemorragia periintraventricular (HPIV); convulsões neonatais; traumatismo craniano; suspeita familiar de atraso de audição ou linguagem e otites médias recorrentes ou persistentes.

Em um levantamento dos resultados obtidos em oito anos (1992-1999) de realização da TAN em 57 hospitais do Colorado, foram avaliados 148.240 recém-nascidos, sendo que 291 recém-nascidos (1/650 nascidos vivos) receberam o diagnóstico de perda auditiva congênita; deste total, $47 \%$ apresentaram um ou mais fatores de risco para perda de audição ${ }^{(4)}$.

Vários autores analisaram a relação entre indicadores de risco e perda de audição ${ }^{(5-10)}$.

A permanência em Unidades de Terapia Intensiva (UTI) Neonatal é um indicador de risco de grande ocorrência. Neonatos prematuros, em geral, nascem com baixo peso, necessitam de ventilação mecânica prolongada e podem apresentar hiperbilirrubinemia em níveis que exijam exsangüineotransfusão, sendo necessário alojá-los na UTI Neonatal.

De acordo com a Organização Mundial de Saúde, são considerados recém-nascidos pré-termo aqueles com idade gestacional inferior a 37 semanas.

Estudos mostram que a incidência de alteração auditiva em neonatos da UTI é maior se comparada à incidência desta alteração em neonatos do berçário comum ${ }^{(8,11)}$.

As infecções congênitas (rubéola, sífilis, citomegalovírus, herpes, toxoplasmose e AIDS), mesmo quando assintomáticas, podem causar deficiência auditiva no neonato e podem estar associadas ao aparecimento tardio da perda auditiva e/ou à progressão da perda auditiva já existente ao nascimento $^{(12-14)}$.

Antibióticos, principalmente a gentamicina e a amicacina, são amplamente utilizados para tratamento de infecções em recém-nascidos, com objetivo terapêutico e profilático, especialmente naqueles provenientes de $\mathrm{UTI}^{(15-16)}$. Estes fármacos são ototóxicos, pois lesam a cóclea, prejudicando o funcionamento coclear e levando à deficiência auditiva ${ }^{(17)}$. Além disso, podem provocar perda auditiva de efeito tardio, assim como as infecções congênitas e perdas auditivas de origem genética.

A importância da pesquisa dos indicadores de risco para a deficiência auditiva infantil está relacionada principalmente ao fato de que muitos destes indicadores podem levar ao aparecimento tardio de perda auditiva e/ou a progressão da perda auditiva já existente ao nascimento. Segundo o Comitê Brasileiro sobre Perdas Auditivas na Infância ${ }^{(18)}$, os recémnascidos que apresentarem tais indicadores de risco requerem avaliação auditiva pelo menos a cada seis meses até a idade de três anos.

Desta forma, neonatos com indicadores de risco preci- sam de acompanhamento auditivo criterioso. As crianças consideradas de risco para distúrbios de audição devem ser submetidas a uma avaliação auditiva no início da vida e a um acompanhamento audiológico, que permita monitorar o desenvolvimento das habilidades auditivas e identificar qualquer tipo de alteração auditiva, ainda no período ideal de estimulação, isto é, no período crítico para a aquisição da linguagem ${ }^{(19)}$. A justificativa deste estudo está centrada na necessidade de conhecer a ocorrência dos indicadores de risco para que se possa realizar medidas de prevenção específicas e eficazes, visando uma diminuição das intercorrências relacionadas ao surgimento da deficiência auditiva infantil.

O objetivo deste estudo foi comparar a ocorrência dos indicadores de risco para a deficiência auditiva infantil ao longo de quatro anos, em um Programa de Triagem Auditiva do Hospital São Paulo da Universidade Federal de São Paulo - UNIFESP.

\section{MÉTODOS}

Esta pesquisa caracteriza-se por um estudo do tipo retrospectivo, e foi aprovada no Comitê de Ética em Pesquisa da UNIFESP.

Foram pesquisados os prontuários de 382 prematuros, 180 recém-nascidos do sexo masculino e 202 do sexo feminino, atendidos no Programa de Triagem e Acompanhamento Multidisciplinar da Universidade Federal de São Paulo UNIFESP, envolvendo o Departamento de Pediatria Neonatal e o Departamento de Fonoaudiologia, no período de 2000 a 2004.

Foi elaborada uma planilha do programa Microsoft Excel contendo os seguintes dados: dados de identificação (nome, sexo, data de nascimento, idade gestacional) e levantamento dos indicadores de risco para a deficiência auditiva infantil.

Foram pesquisados os indicadores de risco de acordo com o protocolo utilizado na UNIFESP(3), adaptado da Joint Committee on Infant Hearing (2000), que consta os seguintes indicadores: permanência em UTI Neonatal por 48 horas ou mais; antecedente familiar de perda auditiva ou consangüinidade, infecções congênitas (rubéola, sífilis, citomegalovírus, herpes, toxoplasmose e AIDS); anomalias craniofaciais incluindo as de pavilhão auricular e meato acústico externo; peso ao nascimento menor que 1500 gramas e/ ou PIG; hiperbilirrubinemia/ exosangüineotransfusão; ototóxicos; meningite bacteriana; Apgar de 0-4 no primeiro minuto e de 0-6 no quinto minuto; ventilação mecânica prolongada; síndromes; alcoolismo materno e/ou uso de drogas psicotrópicas na gestação; hemorragia periintraventricular (HPIV); convulsões neonatais; traumatismo craniano; suspeita familiar de atraso de audição ou linguagem e otites médias recorrentes ou persistentes.

Após a análise de todos os prontuários e da listagem dos indicadores de risco, foi elaborado o estudo estatístico dos dados. Utilizou-se o Teste de Igualdade de Duas Proporções, sendo este um teste não paramétrico, que compara a proporção de respostas de duas determinadas variáveis e/ou seus níveis, avaliando se há ou não diferenças estatisticamente significantes. 


\section{RESULTADOS}

A seguir, serão descritos os indicadores de risco mais freqüentes no tempo do estudo.

Na Figura 1, é possível observar a ocorrência de recémnascidos que permaneceram na UTI neonatal em cada ano.

Os dados apresentados na Figura 2 mostram os indicadores de risco de maior ocorrência em cada um dos anos estudados.

Na Figura 3 são apresentados os indicadores de risco que aumentaram no decorrer dos anos. No ano 2000, foram encontrados sete casos $(5,9 \%)$ de antecedentes familiares/ consangüinidade, os quais aumentaram para 19 casos $(13,6 \%)$ no ano de 2003 (p-valor<0,001). A ventilação mecânica aumentou de 29 casos $(24,6 \%)$ em 2000 para 37 (40,2\%) em 2004 (p-valor $<0,001$ ). O número de convulsões em recémnascidos variou de cinco casos $(4,2 \%)$ em 2000 para nove $(9,8 \%)$ em 2004 (p-valor $<0,001)$. Essas variações com valo- res estatísticos significantes estão expressas na Figura 3.

Na Figura 4, apresenta-se os indicadores de risco para a DA que diminuíram ao longo dos anos. Foram encontrados 13 casos $(11,0 \%)$ de infecção congênita em 2000, o qual decresceu para seis casos $(4,3 \%)$ no ano de 2003 (p-valor $<0,001)$. O outro indicador de risco que diminuiu neste mesmo período foi a hemorragia periintraventricular (HPIV), de 18 casos (15,3\%) no ano 2000 para sete casos (5\%) em 2003 (p-valor $<0,001$ ) .

A Figura 5 evidencia os indicadores de risco para a DA que variaram de forma aleatória no período estudado. Entre eles, os casos de malformação diminuíram de sete $(5,5 \%)$ no ano 2001 para apenas um $(0,7 \%)$ em 2003 (p-valor $<0,001)$. A ocorrência de baixo peso ao nascimento aumentou, sendo que a houve 44 recém-nascidos $(37,3 \%)$ com peso inferior a 1500 gramas em 2000 para 35 (30,7\%) no ano de 2003 (p-valor $<0,001)$. Acrescentam-se os casos de ototoxicidade que diminuíram de $51(43,2 \%)$ em 2000 para 42 (30,0\%) em 2003

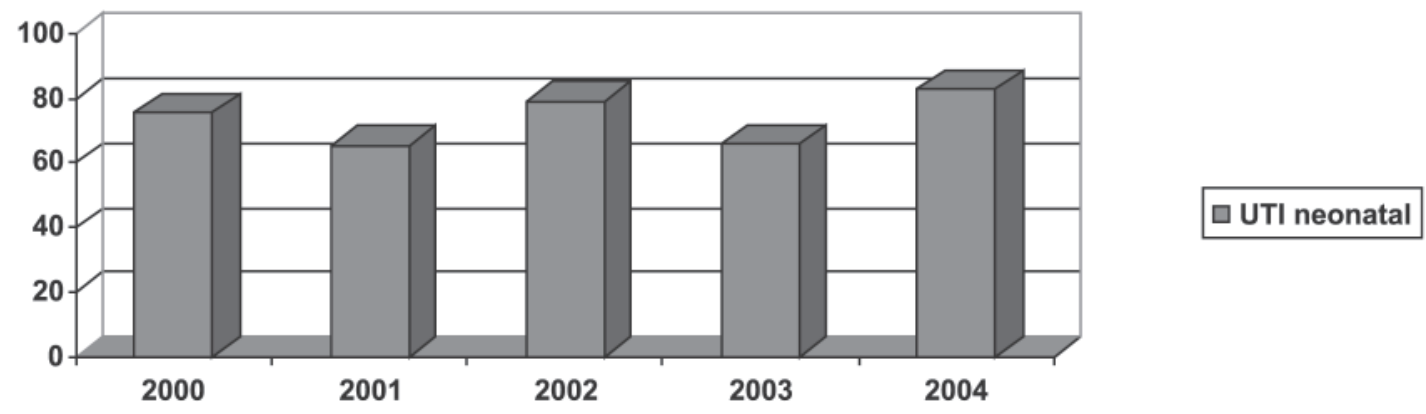

Figura 1. Comparação da ocorrência de RN que permaneceram em UTI neonatal no período de 2000 a 2004

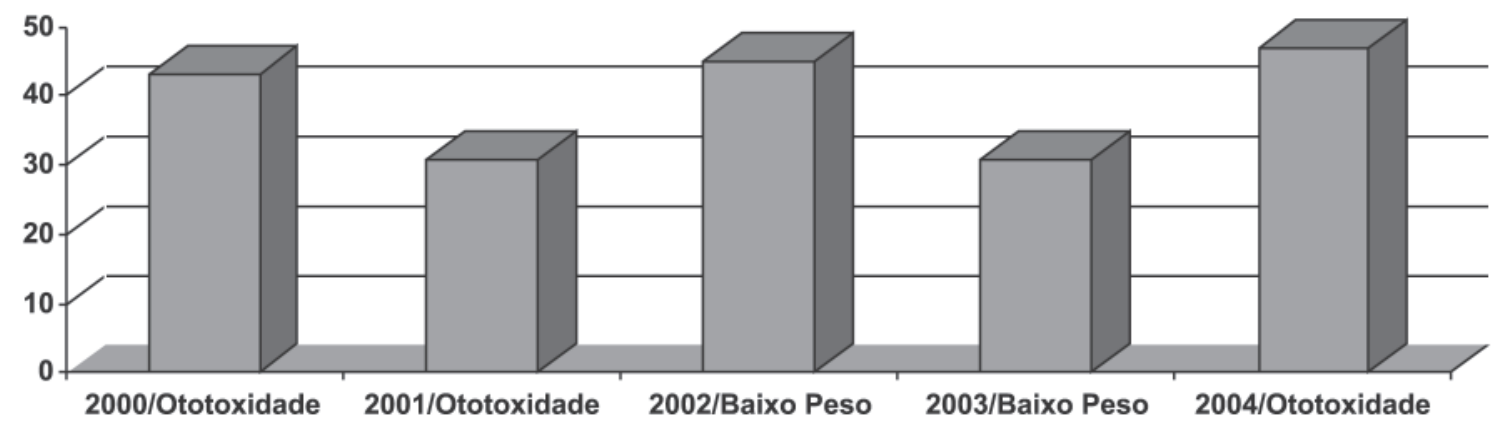

Figura 2. Indicadores de risco de maior ocorrência, por ano, no período de 2000 a 2004

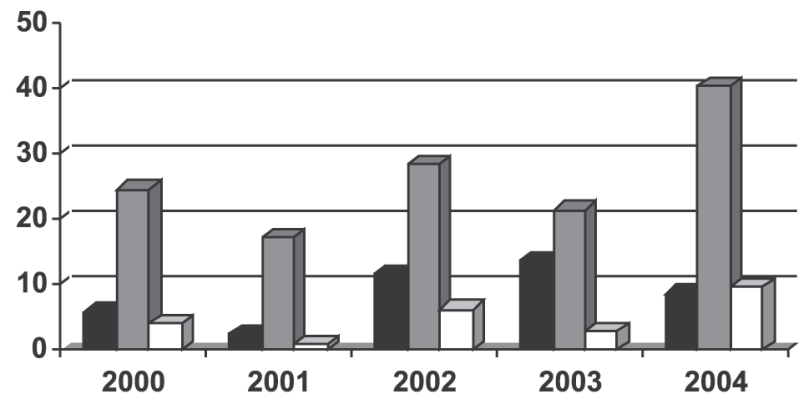

\begin{tabular}{|l|}
$\square$ Antecedentes familiares \\
$\square$ Ventilação \\
$\square$ Convulsão
\end{tabular}

Figura 3. Indicadores de risco para DA que aumentaram no período de 2000 a 2004 


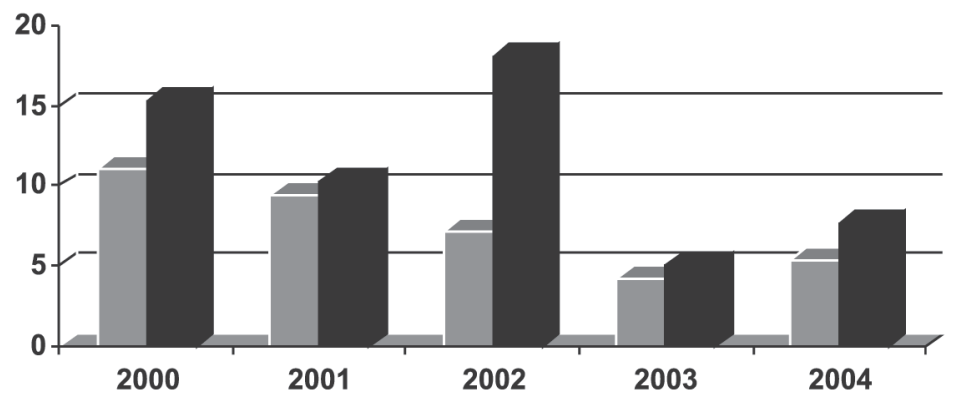

— Infecções Congênitas
HPIV

Figura 4. Indicadores de risco para DA que diminuíram no período de 2000 a 2004
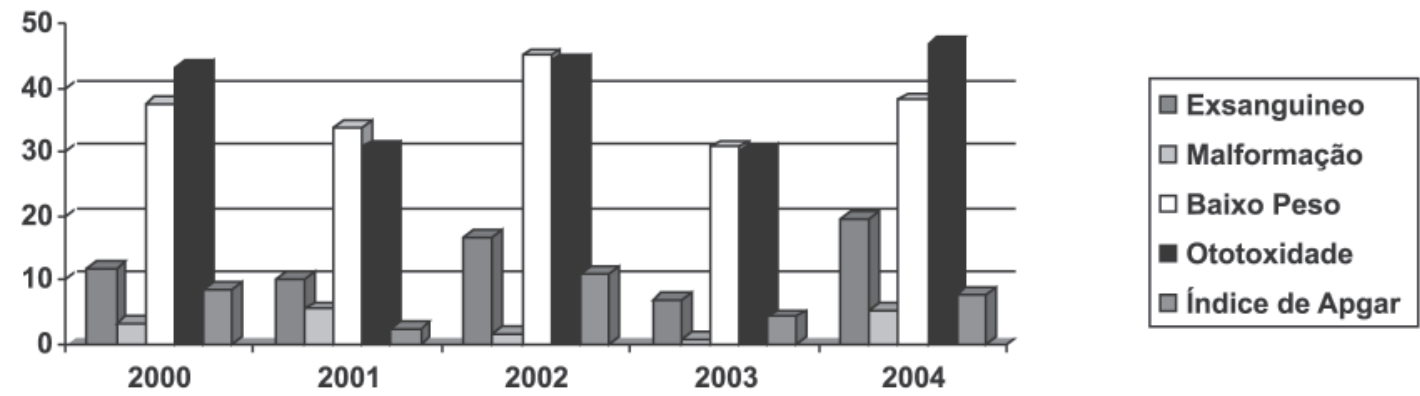

Figura 5. Indicadores de risco para DA que variaram de forma aleatória no período de 2000 a 2004

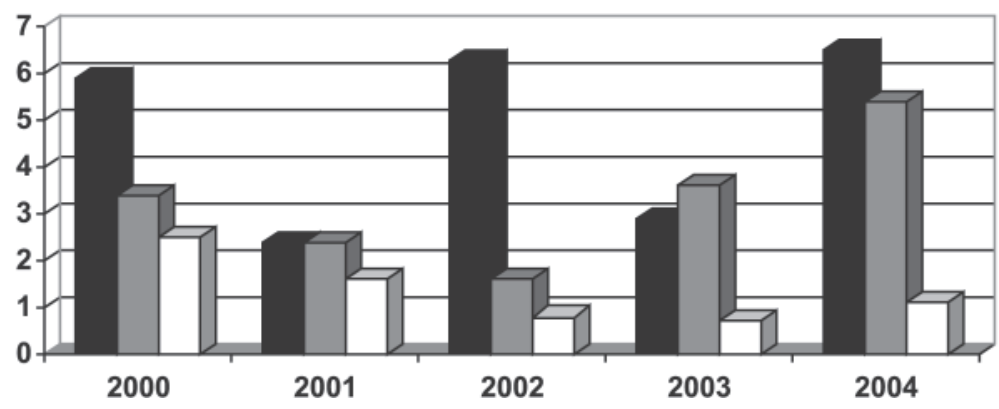

\begin{tabular}{|l|}
\hline Meningite \\
$\square$ Síndromes \\
$\square$ Alcool/Drogas \\
\hline
\end{tabular}

Figura 6. Indicadores de risco para DA que permaneceram estáveis no período de 2000 a 2004

(p-valor<0,001). A indicação de exsangüineotransfusão também variou estatisticamente durante os quatro anos, no ano 2002 para 2003 diminui de 21 casos $(16,5 \%)$ para $10(7,1 \%)$ e aumentou de $10(7,1 \%)$ para $18(19,6 \%)$ de 2003 para 2004 (p-valor<0,001). Além destes, o índice de Apgar de zero a quatro no primeiro minuto ou zero a seis no quinto minuto diminui de 10 ocorrências $(8,5 \%)$ para $3(2,4 \%)$ de 2001 para 2001 e aumentou de $3(2,4 \%)$ para $14(11,0 \%)$ (p-valor $<0,001)$.

Pode-se visualizar na Figura 6 os indicadores de risco para a DA que não sofreram diferença estatisticamente significante ao longo dos anos analisados neste estudo, sendo eles: meningite bacteriana, síndromes e uso de álcool ou drogas durante a gestação.

\section{DISCUSSÃO}

Os avanços científicos e tecnológicos permitiram uma sobrevida de crianças cada vez mais prematuras e foi possível observar uma considerável redução da taxa de mortalida- de neonatal, principalmente dos recém-nascidos provenientes de Unidades de Terapia Intensiva (UTI) Neonatal. Todavia, esta prematuridade pode acarretar várias intercorrências, e conseqüentes seqüelas, entre elas, a alteração auditiva ${ }^{(9)}$.

No presente estudo, comparou-se a ocorrência dos indicadores de risco para a deficiência auditiva infantil ao longo de quatro anos, no Programa de TAN do Hospital São Paulo. Este hospital caracteriza-se por ser um hospital público de referência no atendimento de gestantes de alto risco e atende uma população de nível sócio-econômico baixo.

$\mathrm{O}$ fator de risco mais freqüiente foi à permanência em UTI neonatal com período superior a 48 horas. $\mathrm{O}$ número de recém-nascidos que permaneceram na UTI neonatal, em cada um dos anos, foi em torno de $80 \%$ da amostra. Este dado era esperado visto que a maioria dos RN pré-termo necessita de cuidados intensivos ao nascimento. Além disso, verificou-se uma ocorrência superior a $30 \%$ de RN com muito baixo peso no decorrer dos quatro anos. Os RN de muito baixo peso são mais propensos a infecções e assim necessitam de medicamen- 
tos ototóxicos para que sua sobrevivência possa ser garantida. Dos lactentes de UTI neonatal, em torno de $40 \%$ fizeram uso de medicação ototóxica. A autora comparou a associação entre o uso de drogas ototóxicas e a perda auditiva ${ }^{(16)}$.

Em consequiência da baixa idade gestacional, os recém nascidos apresentaram baixo peso ao nascimento e nestes casos, geralmente, há necessidade de indicação de uso de antibióticos, sendo muitos destes fármacos ototóxicos ${ }^{(16-17)}$.

Ao comparar a ocorrência dos indicadores de risco para a DA, observou-se também que alguns deles aumentaram ao longo do intervalo de tempo investigado, como é o caso dos antecedentes familiares para a deficiência auditiva, da ventilação mecânica e das convulsões neonatais (Figura 3).

No presente estudo, os casos de antecedentes familiares e consangüinidade aumentaram estatisticamente de 2000 para 2003 , de $5,9 \%$ para $13,6 \%$ de ocorrência. Pesquisadores realizaram triagem auditiva neonatal em 322 neonatos e encontraram 27 neonatos $(8,4 \%)$ que apresentavam história familiar para a deficiência auditiva. Os autores pesquisaram a presença deste indicador em um período curto de tempo, sem avaliar variações de sua ocorrência, mas o dado encontrado é próximo ao obtido neste estudo ${ }^{(20)}$.

Em relação à ventilação mecânica, sua ocorrência aumentou significativamente durante os quatro anos, passando de 29 ocorrências $(24,6 \%$ ) para 37(40,2\%) de 2000 para 2004. Um estudo envolvendo 39 recém-nascidos mostrou que 46,7\% destes necessitaram de ventilação mecânica. Os autores verificaram a grande necessidade de ventilação mecânica em neonatos de alto risco, o que concorda com os achados do presente estudo. Acrescenta-se que este fato pode estar relacionado à sobrevida cada vez maior de neonatos prematuros e de baixo peso $^{(21)}$.

O número de convulsões em recém-nascidos aumentou de cinco casos (4,2\%) em 2000 para nove (9,8\%) em 2004. Convulsões representam a manifestação mais característica de comprometimento neurológico no período neonatal. Sua incidência geral é de 4,4 por 1.000 nascidos vivos, variando inversamente ao peso ao nascimento, isto é, quanto menor o peso, maior a probabilidade do recém-nascido apresentar quadros convulsivos ${ }^{(22)}$.

As infecções congênitas e os casos de hemorragia periintraventricular são os indicadores que apresentaram uma diminuição estatisticamente significante ao longo dos anos.

A ocorrência de infecções congênitas diminui estatisticamente de 2000 para 2003, de 13 casos $(11,0 \%)$ para cinco casos $(5,4 \%)$. Ao buscar na literatura estudos que investigassem as taxas de infecções congênitas nos recém-nascidos oriundos de programas de TAN, destaca-se um estudo ${ }^{(20)}$, onde foi realizada TAN em 322 neonatos e não foi encontrado nenhum caso de infecção congênita materna. Cabe ressaltar que este estudo foi realizado em um país desenvolvido, onde são raros os casos de infecções congênitas, situação muito diferente de países em desenvolvimento como o Brasil e em hospitais públicos como o deste estudo.

No Brasil, em um estudo com amostra de 39 recém-nascidos, dois casos de infecção congênita (3,3\% da amostra), sendo estes casos de sífilis ${ }^{(21)}$. Já em um estudo com 174 recém-nascidos, os autores obtiveram 44 de casos de infecção congênita, os quais representam $25,8 \%$ da amostragem $^{(1)}$. Os achados do presente estudo são inferiores aos evidenciados pelos trabalhos citados, mesmo considerando que a ocorrência maior de infecção congênita é encontrada entre as gestantes que correspondem aos segmentos mais empobrecidos da população e com baixa escolaridade, população esta atendida no Hospital São Paulo.

Apesar da pior situação social, as campanhas de prevenção contra as infecções congênitas parecem contribuir para que essas mulheres tenham maior chance de prevenir, diagnosticar e tratar tais infecções. Tal fato pode ser visto como um considerável avanço na área de prevenção da deficiência auditiva em crianças. As campanhas, como instrumento de política pública, são possíveis agentes transformadores da situação atual das infecções congênitas ${ }^{(23)}$.

Neste estudo, a ocorrência de HPIV decresceu de 18 casos $(15,3 \%)$ no ano de 2000 para sete casos (5\%) em 2003. Este achado está relacionado com a maior preocupação dos profissionais envolvidos com os cuidados neonatais, por tratar-se de uma intercorrência que acomete um grande número de recém-nascidos prematuros e por causar sequielas neurológicas nas suas formas mais graves. Além disso, houve o desenvolvimento e o aprimoramento dos exames de diagnóstico precoce da HPIV, como por exemplo, a ultrasonografia transfontanelar e tomografia computadorizada de crânio, que favoreceram a intervenção médica ${ }^{(24)}$.

Em pesquisas realizadas na mesma instituição, Hospital São Paulo, observou-se a ocorrência de HPIV em 8,3\% dos prematuros nascidos nos anos de 1997 a $2001^{(3)}$. Já em outro encontrou nove casos (9\%) de HPIV em 107 recém-nascidos $\operatorname{avaliados}^{(25)}$.

Os casos de malformações crânio-faciais, baixo peso ao nascimento, ototoxicidade, exosanguíneo transfusão e o baixo índice de Apgar representam os indicadores que apresentaram uma variação não-linear de 2000 a 2004, isto é variaram estatisticamente entre os anos, diminuindo em determinados anos e aumentando em outros (Figura 5). Por exemplo, o número de casos de malformações congênitas diminui de sete casos (5,5\%) no ano 2001 para um (0,7\%) em 2003. Alguns estudos apresentam taxas mais elevadas de malformações congênitas ${ }^{(1,20)}$.

A ocorrência de recém-nascidos com baixo peso, isto é, peso inferior a 1500 gramas, variou de 30,7\% a 44,9 \%. Porém, apenas nos anos de 2002 a 2003 houve diferença estatisticamente significante. Dos recém-nascidos de risco para deficiência auditiva 50\% apresentaram o peso ao nascimento inferior a 1500 gramas $^{(21)}$. Em outros estudos que analisaram crianças com perda de audição, que permaneceram na UTI neonatal, observaram que $11 \%^{(8)}$ e $8,6 \%^{(1)}$ da amostra apresentaram baixo peso.

Em nosso estudo, a ototoxicidade em recém-nascidos diminui significativamente apenas de 2000 para 2003, entretanto este indicador esteve presente de $30 \%$ a $46,7 \%$ da amostra, ao longo do período investigado. Como já foi citado anteriormente, antibióticos aminoglicosídeos são amplamente prescritos para o recém-nascido que precisa ser internado em UTI neonatal, por serem eficazes no tratamento de infecções graves ${ }^{(15-17)}$. 
Em estudo realizado com 400 lactentes, todos eles apresentaram pelo menos um fator de risco para a deficiência auditiva, sendo que o indicador com maior ocorrência foi o uso de fármacos ototóxicos ${ }^{(26)}$. No presente estudo, os ototóxicos foram os indicadores de maior ocorrência nos anos de 2000, 2001 e 2004 (Figura 2). Em pesquisas encontradas na literatura, mostram a ocorrência de $18,8 \%^{(1)}$ e $12 \%^{(27)}$ da amostra a ocorrência de uso de ototóxicos.

A necessidade de exsangüineotransfusão nos recém-nascidos do estudo variou estatisticamente entre os anos, diminui de 2002 para 2003 e aumentou de 2003 para 2004. No presente estudo, observamos que o número de casos de exsangüineotransfusão foi inferior a outro estudo ${ }^{(22)}$ encontrado na literatura, uma provável justificativa seja o fato dos recém-nascidos do presente estudo ser provenientes da UTI neonatal. Entretanto, não foram encontrados na literatura dados que justifiquem a variação apresentada na ocorrência de casos de exosangüineotransfusão no intervalo de tempo delimitado neste estudo.

Neste estudo, os indicadores a seguir não apresentaram variações estatisticamente significantes no decorrer dos quatro anos, sendo eles: meningite bacteriana, síndromes e uso de álcool ou drogas durante a gestação, como mostra a Figura 6.

Cabe ressaltar que a maioria dos estudos encontrados na literatura analisou apenas a ocorrência de indicadores de risco para a DA em um determinado período, sendo que não há um acompanhamento desses valores ao longo dos anos. Além disso, não se pode generalizar os dados encontrados em população específica, por exemplo, de um hospital público para um privado. Mas acredita-se que é de extrema relevância que cada hospital ou serviço de saúde ou região conheça e acompanhe a ocorrência de IR para DA, dessa forma possibilitando o planejamento adequado de programas de prevenção.

\section{CONCLUSÃO}

A análise estatística destes dados revelou um aumento significante da ocorrência dos antecedentes familiares para a deficiência auditiva, do uso de ventilação mecânica e as convulsões neonatais, no decorrer dos quatro anos. Os casos de infecção congênita e hemorragia periintraventricular diminuíram estatisticamente do ano 2000 para 2004. Os casos de malformação, baixo peso e ototoxicidade variaram de forma aleatória entre os anos estudados. Alguns indicadores de risco se mantiveram sem alterações estatisticamente significantes, como foi o caso da meningite, uso de álcool e drogas pela gestante e síndromes. Tais achados podem estar relacionados, com o aumento das medidas de prevenção primária que auxiliaram na redução do número de casos das infecções congênitas (imunização contra a rubéola) e/ou o avanço da tecnologia das UTI neonatais que propiciou uma diminuição das hemorragias periintraventriculares e da administração de drogas ototóxicas.

\begin{abstract}
Purpose: To compare the occurrence of risk indicators for hearing loss in children over a period of four years, in a Neonatal Hearing Screening Program. Methods: Three hundred and eighty-two files of preterm infants born at Hospital São Paulo in the period from 2000 to 2004 were researched. Results: In 2000, 5.9\% of the cases showed familiar antecedents and/or consanguinities, while in 2003 this indicator was present in $13.6 \%$ of the population. Mechanical ventilation showed significant increase from $24.6 \%$ in 2000 to $40.2 \%$ of the cases in 2004. The cases of neonatal seizures increased significantly from $4.2 \%$ in 2000 to $9.8 \%$ in 2004 . Congenital infections showed significant decrease from $11.0 \%$ in 2000 to $4.3 \%$ in 2003. In 2002, only one case of syphilis was observed, demonstrating decrease in the occurrence of such diseases. The occurrence of peri-intraventricular hemorrhage significantly decreased from $15.3 \%$ in 2000 to $5 \%$ in 2003 . Malformation cases decreased from $3.4 \%$ in 2000 to $0.7 \%$ in 2003 . Ototoxicity cases showed significant decrease from $43.2 \%$ in 2000 to $30.0 \%$ in 2003. Conclusion: Statistical analysis revealed significant increase of familiar antecedents for hearing loss, use of mechanical ventilation and neonatal seizures during the period considered. Registers of congenital infections and peri-intraventricular hemorrhage showed significant decrease during the same period. Malformation, low birth weight and ototoxicity cases varied randomly, and some risk indicators didn't present any statistically significant variations.
\end{abstract}

Keywords: Hearing loss; Infant, newborn; Risk index; Early diagnosis

\title{
REFERÊNCIAS
}

1. Ruggieri-Marone M, Lichtig I, Marone SAM. Recém-nascidos gerados por mães com alto risco gestacional: estudo das emissões otoacústicas produtos de distorção e do comportamento auditivo. Rev Bras Otorrinolaringol. 2002;68(2):230-7.

2. Harrison M, Roush J, Wallace J. Trends in age of identification and intervention in infants with hearing loss. Ear Hear. 2003;24(1):89-95.

3. Azevedo MF. Triagem auditiva neonatal. In: Ferreira LP, Befi-Lopes DM, Limongi SCO, organizadores. Tratado de fonoaudiologia. São Paulo: Roca; 2004. p. 604-16
4. Mehl AL, Thomson V. The Colorado newborn hearing screening project, 1992-1999: on the threshold of effective population-based universal newborn hearing screening. Pediatrics. 2002;109(1):E7. Comment in: Pediatrics. 2002;110(4):848; author reply 848.

5. Doyle LW, Casalaz D; Victorian Infant Collaborative Study Group. Outcome at 14 years of extremely low birthweight infants: a regional study. Arch Dis Child Fetal Neonatal Ed. 2001;85(3):F159-64.

6. Jiang ZD, Brosi DM, Wilkinson AR. Hearing impairment in preterm very low birthweight babies detected at term by brainstem auditory 
evoked responses. Acta Pediatr. 2001;90(12):1411-5.

7. Maisoun AM, Zakzouk SM. Hearing screening of neonates at risk. Saudi Med J. 2003;24(1):55-7.

8. Peñazola-López YR, Castillo-Maya G, García-Pedroza F, SánchezLópez H. [Hypoacusis-deafness related to perinatal adverse conditions. According to the register available in a specialized unit of Ciudad de Mexico. Analysis according to birth weight]. Acta Otorrinolaringol Esp. 2004;55(6):252-9. Spanish.

9. Suzuki N, Suzumura H. Relation between predischarge auditory brainstem responses and clinical factors in high-risk infants. Pediatr Int. 2004;46(3):255-63.

10. Berg AL, Spitzer JB, Towers HM, Bartosiewicz C, Diamond BE. Newborn hearing screening in the NICU: profile of failed auditory brainstem response/passed otoacoustic emission. Pediatrics. 2005;116(4):933-8. Erratum in: Pediatrics. 2006;117(3):997.

11. Dalzell L, Orlando M, MacDonald M, Berg A, Bradley M, Cacace A, et al. The New York State universal newborn hearing screening demonstration project: ages of hearing loss identification, hearing aid fitting, and enrollment in early intervention. Ear Hear. 2000;21(2):11830. Comment in: Ear Hear. 2000;21(6):640-4.

12. Dahle AJ, Fowler KB, Wright JD, Boppana SB, Britt WJ, Pass RF. Longitudinal investigation of hearing disorders in children with congenital cytomegalovirus. J Am Acad Audiol. 2000;11(5):283-90.

13. Santos PH, Iazzetti AV. Citomegalia congênita e perinatal. Pediatr Mod. 2000;36(12):805-27.

14. Vieira EP, Tochetto TM, Pedroso FS. Indicadores de risco para a deficiência auditiva infantil: infecções congênitas. Fono Atual. 2005;8(32):61-7.

15. Jacob LCB, Aguiar FP, Tomiasi AA, Tschoeke SN, Bitencourt, RF. Monitoramento auditivo na ototoxidade Rev Bras Otorrinolaringol. 2006;72(6):836-44.

16. Câmara MFS. Efeito de fármacos ototóxicos na audição de recémnascidos de alto risco [tese]. São Paulo: Universidade Federal São Paulo. Escola Paulista de Medicina; 2005.

17. Oliveira TMT, Azevedo MF, Vieira MM, Ávila CRB. Triagem auditiva com sons não calibrados: detecção precoce da deficiência auditiva. Acta AWHO. 1995;14(2):88-92.

18. Comitê Brasileiro Sobre Perdas Auditivas Na Infância. Recomendação 01/99 do Comitê Brasileiro Sobre Perdas Auditivas Na Infância. J Cons Fed Fonoaudiol. 2000;5(2):3-7.

19. Yoshinaga-Itano C, Sedey AL, Coulter DK, Mehl AL. Language of early- and later- identified children with hearing loss. Pediatrics. 1998;102(5):1161-71.

20. Watkin PM. Neonatal otoacoustic emission screening and the identification of deafness. Arch Dis Child Fetal Neonatal Ed. 1996; 74(1):F16-25. Comment in: Arch Dis Child Fetal Neonatal Ed. 1996;75(2):F143.

21. Manfredi AKS, Santos CB. Intervenção fonoaudiológica junto às mães ou responsáveis por recém-nascidos de risco para a deficiência auditiva, precocemente detectada. Medicina (Ribeirão Preto). 2002;35(1):70-7.

22. Draque CM. Convulsões no período neonatal In: Carvalho ES, Carvalho WB. Terapêutica e prática pediátrica. 2a ed. São Paulo: Atheneu; 2000. p. 1182-9.

23. Saraceni V, Leal MC. Avaliação da efetividade das campanhas para eliminação da sífilis congênita na redução da morbi-mortalidade perinatal: Município do Rio de Janeiro, 1999-2000. Cad Saúde Pública. 2003;19(5):1341-9.

24. Almeida MFB, Meneguel JF. Hemorragia periintraventricular do prematuro. In: Carvalho ES, Carvalho WB. Terapêutica e prática pediátrica. 2a ed. São Paulo: Atheneu; 2000. p. 1178- 82.

25. Guerrero SM. Avaliação auditiva comportamental e eletrofisiológica em recém-nascidos pré-termo com e sem indicadores de risco para alteração auditiva [tese]. São Paulo: Universidade Federal São Paulo. Escola Paulista de Medicina; 2006.

26. Garza Morales S, Poblano A, Robledo Galván A, Fernández Carrocera LA. Potenciales provocados auditivos em niños con riesgo neonatal de hipoacusia. Rev Panam Salud Pública. 1997;1(2):119-24.

27. Sassada MMY, Ceccon MEJ, Navarro JM, Vaz FAC. Deficiência auditiva em recém-nascidos internados em unidade de terapia intensiva neonatal. Pediatria (São Paulo). 2005;27(3):163-71. 